\title{
AS MISSÕES DE OBSERVAÇÃO DA ORGANIZAÇÃO DOS ESTADOS AMERICANOS NAS ELEIÇÕES DA AMÉRICA LATINA
}

\author{
THE MISSIONS OF OBSERVATION THE ORGANIZATION OF AMERICAN STATES IN \\ THE ELECTIONS IN LATIN AMERICA
}

Dyogo Crosara ${ }^{1}$

\begin{abstract}
Resumo:O presente artigo visa analisar como estão sendo desenvolvidas as missões de observações eleitorais pela Organização dos Estados Americanos (OEA), na fiscalização de tais pleitos e qual a relevância dos relatórios que estão sendo apresentados pela entidade. Nos últimos anos, os regimes democráticos vigentes na América Latina têm sido enormemente questionados. Movimentos autoritários de direita e de esquerda vêm questionando a lisura das eleições e de vários resultados. Claramente, existem grupos interessados em gerar uma instabilidade nas estruturas das instituições, numa busca absurda por mais espaço de poder. No epicentro dessa discussão está o papel das observações realizadas pela Organização dos Estados Americanos (OEA), que envia seus representantes para o acompanhamento dos processos eleitorais. Tais relatórios, porém, não estão tendo a repercussão necessária para coibir as críticas apresentadas e tampouco para referendar os resultados dos pleitos. Analisamos algumas das últimas participações da OEA, em especial na Bolívia, em 2019, e nas eleições gerais no Brasil, em 2018, onde o atual Presidente da República questiona a segurança das urnas de votação, numa luta para que o sistema seja alterado de voto eletrônico para a votação em papel, podendo concluir pela necessidade de reformulação do formato das missões e do poder de coerção de suas decisões.
\end{abstract}

Palavras-chave: Organizações internacionais; democracia; América Latina; eleições; Organização dos Estados Americanos.

\begin{abstract}
This article aims to analyze how electoral observation missions are being carried out by the Organization of American States - OAS, in the inspection of such elections and the relevance of the reports that are being presented by the entity. In recent years the democratic regimes in Latin America have been questioned enormously. Authoritarian movements of the right and left have been questioning the fairness of the elections and various results. Clearly, there are groups interested in generating instability in the structures of institutions in an absurd search for more power. At the epicenter of this discussion is the role of the observations made by the Organization of American States - OAS that sends their representatives to monitor the electoral processes. However, such reports are not having the necessary repercussions to curb the criticisms presented and not even to endorse the results of the claims. We analyze some of the latest OAS holdings, in Bolivia in 2019 and in the elections in Brazil in 2018, where the current President of the Republic questions the security of the ballot boxes, in a fight for the system to be changed from electronic voting to voting on paper and may conclude for the need to reformulate the format of the missions and the power to coerce their decisions.
\end{abstract}

Keywords: International organizations; democracy; Latin America; elections; Organization of American States.

\section{Introdução}

No cotidiano atual de alguns países da América Latina repetem-se questionamentos, por parte de populares e até mesmo de algumas autoridades, sobre a higidez e a importância da democracia. Por mais absurdo que possa ser, temos visto que alguns dirigentes populistas,

\footnotetext{
${ }^{1}$ Aluno do Mestrado em Direito e Ciência Política da Universidade Lusófona. E-mail: dyogo@crosara.adv.br.
} 
eleitos pela soberania das urnas, não têm tido o menor pudor de questionar a legitimidade das eleições e, inclusive, de algumas instituições de Estado.

A instabilidade democrática não é uma novidade para tais nações, que conviveram, no século XX, com vários movimentos antidemocráticos, especialmente com ditaduras implantadas por regimes militares. Todavia, é inegável que, na última década, alguns países têm feito a opção por Presidentes que tem se mostrado descompromissados com a defesa dos ideais democráticos, negando, também, aquilo que prometeram em seus juramentos constitucionais.

Nesse cenário, muito se indaga sobre quem pode ajudar a América Latina a evitar uma escalada de movimentos ditatoriais, a exemplo do que ocorreu após o golpe de março de 1964, no Brasil, e se espalhou por todas as nações do chamado Cone Sul.

Uma das respostas aponta para a Organização dos Estados Americanos (OEA), tida como o mais antigo organismo internacional do mundo (OEA, 2021), que possui, em sua Carta (OEA, [1948]) matriz, a previsão que um dos princípios da entidade é de promover e consolidar a democracia representativa, respeitado o princípio da não intervenção (artigo 2, "b”, da Carta da Organização dos Estados Americanos - A-41).

Todavia, necessária se mostra a análise do que efetivamente a organização tem realizado para a defesa, dessa feita, de sua carta constitutiva, especialmente durante os pleitos eleitorais, o que discorreremos doravante.

Como instrumento de tal atuação, a OEA tem realizado missões de acompanhamento dos processos eleitorais em vários países membros, com destaque para as realizadas na América Latina, cujos relatórios trazem uma série de impressões e apontamentos sobre a própria saúde democrática de tais nações.

Como em vários organismos internacionais, existem questionamentos sobre o papel de instituições como a Organização dos Estados Americanos, alvo de acusações daqueles que tentam o enfraquecimento de entes de regulação e mediação de conflitos, muitas vezes por interesses políticos pessoais, que só visam a perpetuação no poder.

Cabe-nos analisar as razões de tais missões dentro do papel de defesa dos princípios democráticos, bem como a efetividade de seus relatórios, especialmente num ambiente de aumento da instabilidade política que essas nações estão passando.

2 As missões da Organização dos Estados Americanos para observação de eleições na América Latina 


\subsection{Aspectos relevantes das missões de observação eleitoral}

Segundo a Organização dos Estados Americanos (OEA), a entidade realizou, desde 1962, mais de 240 missões de observação eleitoral (MOEs) em 27 países do continente americano, conforme colhido da publicação OEA: 50 anõs observando elecciones el Las Américas.

A partir das primeiras missões, nas quais o essencial era ter uma presença simbólica no país-anfitrião, as observações eleitorais hoje incorporam metodologias específicas que refletem a maior complexidade dos processos políticos e sociais pelos quais passam o continente durante os últimos 50 anos. Depois de meio século acompanhando eleições, a OEA continua aperfeiçoando suas metodologias, com o firme propósito de colaborar com o fortalecimento dos processos democráticos de seus Estados-membros. Misiones de Observación Electoral de primera generación: la presencia, a primeira missão eleitoral da OEA, ocorreu em fevereiro de 1962, na Costa Rica.

Sob a responsabilidade do cidadão chileno Manuel Bianchi, a organização enviou, a pedido do governo, uma missão de assistência técnica para observar as eleições presidenciais no país da América Central. Nesse mesmo ano, na República Dominicana, o Presidente Joaquín Balaguer introduziu uma série de reformas no sistema político para o qual solicitou a assistência técnica da OEA. Ambos os casos antecederiam o que hoje conhecemos como Misiones de Observación Electoral de la Organización.

Entre 1962 e 1989 houve Misiones de Observación em 25 eleições de onze países-membros da OEA: Costa Rica, República Dominicana, Honduras, Nicarágua, Bolívia, Equador, Guatemala, Panamá, El Salvador, Grenada e Suriname. Essas Misiones, hoje chamadas como de primeira geração, poderiam ser caracterizadas como um acompanhamento político, simbólico e presencial de testemunhas internacionais no processo eleitoral. Cabe mencionar que esse período foi marcado pelo domínio de sistemas autoritários na região, motivo pelo qual a prática de observar eleições não se consolidou de forma massiva. (OEA, 2012, p. 4). ${ }^{2}$

\footnotetext{
2 Tradução nossa de: "Desde una primera generación de misiones donde lo esencial era tener una presencia simbólica en el país anfitrión, las observaciones electorales hoy incorporan metodologías específicas que reflejan la mayor complejidad de los procesos políticos y sociales que ha experimentado el continente durante los últimos 50 años. Tras medio siglo observando elecciones, la OEA continúa perfeccionando sus metodologías con el firme propósito de colaborar al fortalecimiento de los procesos democráticos de sus Estados Miembros Misiones de Observación Electoral de primera generación: la presencia La primera Misión Electoral de la OEA se desplegó en febrero de 1962 en Costa Rica. A cargo del ciudadano chileno Manuel Bianchi, la Organización envió, a solicitud del gobierno, una misión de asistencia técnica para que observara las elecciones presidenciales en el país centroamericano. Ese mismo año, en República Dominicana, el Presidente Joaquín Balaguer comenzó a introducir una serie de reformas al sistema político para lo cual solicitó la asistencia técnica de la OEA. Ambos casos se convertirían en los primeros antecedentes de lo que hoy conocemos como Misiones de Observación Electoral de la Organización. Entre 1962 y 1989 hubo Misiones de Observación en 25 elecciones de once países Miembros de la OEA: Costa Rica, República Dominicana, Honduras, Nicaragua, Bolivia, Ecuador, Guatemala, Panamá, El Salvador, Grenada y Suriname. Estas Misiones, hoy llamadas de primera generación, podrían caracterizarse como un acompañamiento político, simbólico y presencial de testigos internacionales en el proceso electoral. Cabe mencionar que este período estuvo marcado por el dominio de sistemas autoritarios en la región, por lo que la práctica de observar elecciones no se consolidó de forma masiva.” (OEA, 2012, p. 4).
} 
Sem embargo, a institucionalização das missões se deu apenas após a Assembleia Geral de 11 de setembro de 2001, realizada em Lima, no Peru, quando a Organização dos Estados Americanos aprovou a Carta Democrática Interamerica (OEA, 2001), considerada um

[...] manifesto em favor da democracia representativa nas Américas, trazendo um conceito de democracia que transcende (termo usado na Carta) a ideia de democracia eleitoral. [...] Esta transcendência decorre da inclusão do "governar democraticamente" por meio do respeito aos direitos humanos e liberdades fundamentais, do acesso ao poder, da separação e independência dos Poderes (artigo $3^{\circ}$ da Carta), etc. (MARQUES; GALVÃO, 2020, p. 191192).

Referida carta, que não se pode ser considerada um tratado, mas sim uma soft law $w^{3}$, prevê que os povos da América têm direito à democracia e seus governos têm a obrigação de promovê-la e defendê-la, conforme estampado em seu primeiro artigo.

Dentre os instrumentos para a avaliação do processo democrático, referida Carta previu, de forma clara, a possibilidade de realização de missões de observação dos processos eleitorais, conceituadas pela própria OEA, no Observando los Sistemas de Financiamiento PolíticoElectoral: Un Manual para las Misiones de Observación Electoral de la Organización de los Estados Americanos (OEA, 2006).

[...] como um procedimento pelo qual um grupo organizado de pessoas alheias ao país-anfitrião realiza, de forma sistemática, um conjunto de ações e atividades complexas para constatar de forma direta, completa e exata, um processo eleitoral. O objeto da observação é o processo. ${ }^{4}$

Importante anotar que na Carta Democrática Interamerica há um capítulo estabelecendo as regras gerais das missões, prevendo o texto que

A democracia e as missões de observação eleitoral

\footnotetext{
${ }^{3}$ Entende-se por soft law as normas consideradas como recomendações, cujo teor levam a preceitos que incentivam determinadas condutas, sem, no entanto, estabelecerem uma obrigatoriedade ou sanção pelo seu descumprimento. Entretanto, faz-se imperioso destacar que não há um conceito único para o termo soft law e que, para os fins do presente estudo, abordaremos apenas as características fundamentais do instituto. Para Shelton, esse termo se refere a qualquer instrumento internacional, além dos tratados, que contenham princípios, normas, padrões ou outras declarações de comportamento esperado. Sob esse ponto de vista, orientações internacionais, sem a força vinculativa de tratados, possuem o condão de influenciar nas instituições de direito interno, conforme veremos adiante. Adotando os critérios de Shelton, podemos aferir como características do soft law: (i) ser juridicamente não vinculativa; (ii) consistente, em geral, em normas ou princípios e não regras; (iii) norma não imediatamente aplicável por meio de mecanismos de resolução de conflitos; (iv) não estabelecimento de regras obrigatórias e; (v) apontado como um primeiro passo no processo legislativo internacional. Nesse sentido, a autora conclui que "a utilização de instrumentos de soft law como recomendações, códigos de prática ou normas, é importante para indicar a constituição de diretrizes que tenham o potencial de posteriormente transformarem-se em regras juridicamente vinculativas" (SHELTON, 2010, p. 160).

${ }^{4}$ Tradução nossa de: [...] como un procedimiento mediante el cual un grupo organizado de personas ajenas al país anfitrión lleva a cabo, en forma sistemática, un conjunto de acciones y actividades complejas para constatar en forma directa, completa y exacta un proceso electoral. El objeto de la observación es el proceso.” (OEA, 2006).
} 
Artigo 23

Os Estados membros são os responsáveis pela organização, realização e garantia de processos eleitorais livres e justos.

Os Estados membros, no exercício de sua soberania, poderão solicitar à OEA assessoria ou assistência para o fortalecimento e o desenvolvimento de suas instituições e seus processos eleitorais, inclusive o envio de missões preliminares com esse propósito.

Artigo 24

As missões de observação eleitoral serão levadas a cabo a pedido do Estado membro interessado. Com essa finalidade, o governo do referido Estado e o Secretário-Geral celebrarão um convênio que determine o alcance e a cobertura da missão de observação eleitoral de que se tratar. O Estado membro deverá garantir as condições de segurança, livre acesso à informação e ampla cooperação com a missão de observação eleitoral.

As missões de observação eleitoral realizar-se-ão em conformidade com os princípios e normas da OEA. A Organização deverá assegurar a eficácia e independência dessas missões, para o que as dotará dos recursos necessários. Elas serão realizadas de forma objetiva, imparcial e transparente, e com a devida capacidade técnica.

As missões de observação eleitoral apresentarão oportunamente ao Conselho Permanente, por meio da Secretaria-geral, os relatórios sobre suas atividades. Artigo 25

As missões de observação eleitoral deverão informar o Conselho Permanente, por meio da Secretaria-Geral, caso não existam as condições necessárias para a realização de eleições livres e justas.

A OEA poderá enviar, com o acordo do Estado interessado, missões especiais a fim de contribuir para criar ou melhorar as referidas condições. (OEA, 2001).

Assim, as missões visam o acompanhamento dos processos eleitorais, precipuamente para garantir que os princípios democráticos previstos pela Carta Democrática Interamericana sejam de fatos respeitados pelos países-membros, desde a fase prévia até a posse dos eleitos.

Como visto pelo texto da Carta, as missões são iniciadas a partir de um convite do paísmembro, ou seja, a regra geral é que ela seja levada a cabo a pedido do Estado interessado. Tal fato, por exemplo, ocorreu no Brasil, nas eleições presidenciais de 2018, como se observa pelo Relatório Final da Missão, que previu, em seu intróito:

Em 19 de setembro de 2017, a Secretaria-Geral da Organização dos Estados Americanos (SG/OEA) recebeu um convite oficial do Governo da República Federativa do Brasil para alocar uma Missão de Observação Eleitoral (MOE) para observar as eleições gerais de 7 de outubro de 2018 e, se fosse o caso, o segundo turno de 28 de outubro de 2018. Em 21 de setembro de 2017, o Secretário-Geral Luis Almagro aceitou o convite e deu instruções ao Departamento de Cooperação e Observação Eleitoral (DECO) da Secretaria para o Fortalecimento da Democracia (SFD) para iniciar os preparativos correspondentes e administrar a busca de recursos externos para o seu financiamento. Para esta ocasião, o Secretário-Geral da OEA nomeou a exPresidente da Costa Rica, Laura Chinchilla como Chefe da Missão.

Em 11 de dezembro de 2017, o Ministro Presidente do Tribunal Superior Eleitoral (TSE) do Brasil, Gilmar Mendes,2 e o Secretário-Geral da Organização dos Estados Americanos (SG/OEA), Luis Almagro, assinaram 
em Washington, D.C., o acordo relativo aos procedimentos de observação das eleições gerais de 2018. Em 23 de agosto de 2018, o Ministro das Relações Exteriores, Aloysio Nunes e a Chefe da Missão, Laura Chinchilla, assinaram em Brasília o acordo para que a Missão pudesse realizar o seu trabalho com independência.

Nos seus esforços para apoiar os Estados-Membros a fortalecer as suas instituições democráticas, pela primeira vez, a Organização dos Estados Americanos alocou uma Missão de Observação Eleitoral no Brasil e, como tal, constituiu uma oportunidade histórica para a promoção do trabalho da OEA em uma das maiores democracias do continente. (OEA, 2018, p. 3).

Assim, as missões são realizadas a partir de um pedido, ou seja, a possibilidade de fiscalização só ocorre quando há concordância do Estado-Membro. Tal fato é motivo de críticas, visto que as missões são também necessárias em casos onde o Estado-Membro pode se recusar a enviar o convite formal para a sua realização. Todavia, como não há norma cogente para obrigar a receber as missões, eleições com riscos de fraude podem deixar de serem fiscalizadas pela OEA.

É evidente que em alguns casos pode se perceber uma possível pressão diplomática da OEA e de seus membros para a aceitação das missões, mas, em todos os casos verificados, o pedido é essencial. Importante destacar que até mesmo no acompanhamento das eleições gerais da Bolívia, em 2019, houve um acordo entre a Organização e o Gobierno del Estado Plurinacional de Bolivia prevendo a realização da missão (OEA, 2019a).

As missões de acompanhamento eleitoral, realizadas a pedido do Estado-Membro, não afastam a possibilidade de instituição de gestões diplomáticas em caso de verificação de alteração da ordem constitucional, algo também previsto pela Carta de Lima. ${ }^{5}$

O procedimento do artigo 20 da Carta Democrática Interamerica é um instrumento que pode ser usado não apenas durante os pleitos eleitorais, mas também em casos de grave risco à democracia, como ocorreu, por exemplo, com a Venezuela, em $2016 .{ }^{6}$

\footnotetext{
${ }^{5} \mathrm{O}$ artigo 20 da Carta Democrática Interamericana, também chamada Carta de Lima, prevê que: "Caso num Estado membro ocorra uma alteração da ordem constitucional que afete gravemente sua ordem democrática, qualquer Estado membro ou o Secretário-Geral poderá solicitar a convocação imediata do Conselho Permanente para realizar uma avaliação coletiva da situação e adotar as decisões que julgar convenientes. O Conselho Permanente, segundo a situação, poderá determinar a realização das gestões diplomáticas necessárias, incluindo os bons ofícios, para promover a normalização da institucionalidade democrática. Se as gestões diplomáticas se revelarem infrutíferas ou a urgência da situação aconselhar, o Conselho Permanente convocará imediatamente um período extraordinário de sessões da Assembléia Geral para que esta adote as decisões que julgar apropriadas, incluindo gestões diplomáticas, em conformidade com a Carta da Organização, o Direito Internacional e as disposições desta Carta Democrática. No processo, serão realizadas as gestões diplomáticas necessárias, incluindo os bons ofícios, para promover a normalização da institucionalidade democrática.” (OEA, 2001).

${ }^{6}$ Em maio de 2016, foi apresentado pedido da Assembleia Geral Venezuelana ao Secretário Geral solicitando a aplicação da Carta Democrática da OEA, tendo sido convocado o Conselho Permanente para analisar o pleito em
} 
É evidente que seria fundamental, para o melhor acompanhamento dos pleitos eleitorais, se houvesse um tratado ououtro instrumento legal a obrigar os países-membros da OEA a receber as missões. Poderá existir casos onde o país-membro se recuse a enviar o convite para que a entidade atue na fiscalização do pleito, prejudicando o cumprimento da Carta Democrática Interamericana, bem como da Carta de Organização da Organização dos Estados Americanos.

Definida a realização da missão, o rito atualmente seguido prevê que seja assinado o acordo de procedimentos para a observação eleitoral, subscrito pelas autoridades eleitorais do país anfitrião e pelo Secretário Geral da organização, estabelecendo as condições em que se desenrolará a observação.

Em seguida, é formada a comissão de observadores, que reúne autoridades de vários países-membros, muitos deles ligados ao Poder Judiciário, buscando sempre assegurar uma representação de várias regiões do hemisfério em sua formação.

Tais membros agem como testemunhas

[...] daquilo que observam e emitir um parecer sobre a credibilidade do processo eleitoral em função de critérios relativos à honestidade e ao caráter democrático da eleição, e à aplicação da lei eleitoral e dos procedimentos aprovados, levando em consideração princípios democráticos fundamentais. Este mandato consiste também, embora de maneira indireta, de favorecer a implantação de melhores sistemas eleitorais. (LE DIRECTEUR GÉNÉRAL DES ÉLECTIONS DU QUÉBEC, [2021], p. 17).

Importante anotar que os observadores devem seguir o Código de Conduta para observadores eleitorais ${ }^{7}$, documento editado pelas Nações Unidas em 27 de outubro de 2005, mas também exigido para os observadores eleitorais das missões da OEA.

Embora a face mais visível das missões seja a visita dos observadores durante o dia de votação, elas se iniciam de forma bastante antecipada, envolvendo uma importante fase préeleitoral, que envolve a análise das normas vigentes, as funções das autoridades eleitorais e a independência dos órgãos, as atividades dos governos, das forças armadas, dos meios de comunicação e das organizações sociais.

Além disso, as missões analisam o processo de votação, acompanhando a preparação das urnas, da lista de eleitores aptos, a instalação dos locais e mesas de votação, a fiscalização

sessão extraordinária. Tal fato acabou por gerar um ato do Presidente da Venezuela, solicitando a retirada do País da OEA. Sobre o tema, importante as anotações de Drezza (2017).

${ }^{7}$ O Código pode ser encontrado em Naciones Unidas (2005). 
realizada por partidos políticos, os eventuais atos de fraude, a segurança do voto, o respeito ao voto secreto e até mesmo o desempenho de outros observadores internacionais.

Outro aspecto avaliado pela missão é a apuração dos votos, algo que ficou muito em evidência após a divulgação do relatório final das Elecciones Generales en el Estado Plurinacional de Bolivia, onde foram apuradas irregularidades na apuração do votos. Do relatório constou expressamente que

As manipulações e irregularidades assinaladas não permitem ter certeza da margem de vitória do candidato Moreales sobre o candidato Mesa. Ao contrário, a partir da esmagadora evidência encontrada, é possível afirmar que houve uma série de operações dolosas encaminhadas de modo a alterar a vontade expressa nas urnas.

Em primeiro lugar, na noite da eleição, o tribunal eleitoral interrompeu de maneira deliberada a transmissão de resultados. Todas as análises da equipe técnica permitem determinar que a paralização do sistema TREP não foi um acidente nem uma decisão baseada em fundamentos técnicos. Foi simplesmente uma decisão arbitrária, cujo propósito incluiu a manipulação da infraestrutura informática. (OEA, 2019b). ${ }^{8}$

Aliás, a missão da OEA nas eleições bolivianas de 2019 traz um capítulo a parte na história recente da instituição. Cercada de grande expectativa, ela foi fundamental para a comunidade internacional entender que a nova eleição do então Presidente Evo Morales teria sido fraudada (OEA, 2019b) ${ }^{9}$

Passados meses do relatório final, que pode ser considerado como fator que desencadeou a derrubada do Governo local, vários veículos de imprensa, especialmente nos Estados Unidos, passaram a apontar falhas no relatório e a ausência de imparcialidade dos observadores internacionais. $^{10}$

\footnotetext{
${ }^{8}$ Tradução nossa de: "Las manipulaciones e irregularidades señaladas no permiten tener certeza sobre el margen de victoria del candidato Morales sobre el candidato Mesa. Por el contrario, a partir de la abrumadora evidencia encontrada, lo que sí es posible afirmar es que ha habido una serie de operaciones dolosas encaminadas a alterar la voluntad expresada en las urnas. En primer lugar, la noche de la elección, el tribunal electoral interrumpió de manera deliberada la transmisión de resultados. Todos los análisis del equipo técnico permiten determinar que la paralización del sistema TREP no fue un accidente ni una decisión basada en fundamentos técnicos. Fue simplemente una decisión arbitraria, cuyo propósito incluyó la manipulación de la infraestructura informática." (OEA, 2019b).

${ }^{9} \mathrm{O}$ relatório foi muito contundente ao afirmar que "a equipe auditora detectou uma manipulação dolosa dos comícios em dois planos. No âmbito das atas, a partir da alteração destas e da falsificação das assinaturas dos mesários. No âmbito do processamento dos resultados, a partir do redirecionamento do fluxo de dados a dois servidores ocultos e não controlados por pessoal do TCE, sendo possível a manipulação de dados e a alteração de atas. Somam-se a isso irregularidades graves, como falta de resguardo das atas e a perda de material sensível. Esses achados revelam, então, a parcialidade da autoridade eleitoral. Os representantes do TSE, que deveriam zelar pela legalidade e integridade do processo, permitiram que se desviasse o fluxo de informação até servidores externos, destruindo toda a confiança no processo eleitoral.” (OEA, 2019b, p. 10, tradução nossa).

${ }^{10}$ Interessante, sobre o tema, a reportagem publicada pelo site Intercept Brasil, onde constou o seguinte trecho que merece destaque: "Desde o início havia motivos para duvidar seriamente, senão rejeitar completamente, as
} 
As missões também já tem trazido, em seus relatórios, preocupações com questões que tem se mostrado fundamentais para os próximos pleitos. No relatório realizado sobre as últimas eleições gerais no Brasil, foi interessante anotar uma crítica sobre a liberdade de expressão durante o período pré-eleitoral, tendo sido constatado que

A MOE/OEA considera que algumas declarações feitas durante a campanha tiveram um tom discriminatório e excludente. Visando ao segundo turno, a Missão solicitou aos candidatos que centrem suas campanhas fazendo propostas à sociedade em vez de desqualificar ou estigmatizar os adversários. [...] Um dos mais complexos desafios criados pela campanha eleitoral é a disseminação de notícias falsas, atribuídas a seguidores de diferentes setores políticos, por meio das redes sociais e serviços de mensagens na Internet. Embora este fenômeno já tenha sido visto nos processos eleitorais de outros países, as eleições do Brasil apresentaram novos desafios, tais como a utilização de sistemas criptografados para difusão massiva de desinformação. Apesar dos esforços feitos no Brasil para combater a desinformação, a Missão notou que a proliferação de informação falsa observada por ocasião das eleições do dia 7 de outubro passado intensificou-se no segundo turno das eleições, alastrando-se para outras plataformas digitais, como o Whatsapp. A natureza desta ferramenta, um serviço criptografado de mensagens privadas, dificulta o já complexo combate à propagação de notícias falsas. (OEA, 2018, p. 17).

Se mostra bastante relevante esse tema, apontado no relatório apresentado sobre as eleições gerais no Brasil em 2018, questão de grande importância e que tem se repetido em outras nações, algo que também deve constar no relatório das eleições seguintes a serem observadas.

Ao longo do presente artigo, pude verificar que algumas das premissas iniciais não se demonstraram ao analisar o que vem sendo desenvolvido. Há, sim, uma análise minudente pela instituição sobre vários aspectos da realidade dos países e também se verifica uma preocupação ampla sobre a preservação do processo democrático. Evidente que as missões podem evoluir, mas elas são, de fato, ferramenta importante para a preservação da democracia no continente americano.

acusações da OEA de irregularidades e fraude nas eleições. Como Jake Johnston, do CEPR, disse hoje em resposta ao artigo do New York Times: 'Para aqueles que estiveram atentos às eleições de 2019, nunca houve qualquer dúvida de que as afirmações de fraude pela OEA eram falsas. Poucos dias após as eleições, um alto funcionário da OEA me confessou, privadamente, que não havia ocorrido uma mudança "inexplicável" na tendência, mas a organização continuou a repetir suas falsas afirmações por muitos meses, com muito pouca ou nenhuma autocrítica ou responsabilização'. [...] Nesse caso, a Bolívia perdeu seu presidente mais bem-sucedido de sua história moderna e, consequentemente, está agora nas mãos de uma junta militar não eleita, aplaudida pelos EUA e sua mídia, se apoiando em um relatório da OEA que, mesmo o New York Times é agora forçado a reconhecer, é, no melhor dos casos, profundamente problemático. Assim, o governo dos EUA e sua mídia, uma vez mais, ajudaram a destruir uma próspera democracia latino-americana." (THE INTERCEPT BRASIL, 2020). 


\subsection{A necessidade de aperfeiçoamento das missões da OEA nas eleições na América Latina}

As missões de observação eleitoral da OEA nos países americanos podem, de fato, ser uma importante ferramenta de fiscalização ao cumprimento dos princípios democráticos, em especial nos países da América Latina. Todavia, se mostra necessário refletir sobre a possibilidade de aperfeiçoamento de tais missões, visando dar mais efetividade ao conteúdo daquilo que é testemunhado pelos observadores internacionais.

Analisando alguns dos relatórios finais de missões realizadas na última década fica patente que eles demonstram alguns caminhos a seguir, sugerindo melhorias e realizando uma análise pormenorizada de desafios e melhorias possíveis. A efetividade, porém, de tais testemunhos depende muito mais da vontade do país-membro em buscar tal aperfeiçoamento do que do poder da entidade em buscar tal melhoria. Como dito anteriormente, o fato de não haver normas legais com poder de coerção aos países-membros retira a efetividade das missões.

Seria necessária uma revisão na própria Carta Democrática Interamericana, prevendo mecanismos que dessem mais efetividade aos relatórios apresentados, fazendo com que a organização realmente tivesse relevância no processo de aperfeiçoamento da democracia nesses países.

Para este estudo, apesar das limitações da OEA, acredita-se que a burocracia da organização tem trabalhado em responder a essas demandas de crises políticas, mas conforme posto pelo próprio Secretário-Geral da OEA (2009, não paginado) sobre a crise de Honduras, há a necessidade de repensar os mecanismos e esclarecer as formas de utilização da Carta Democrática Interamericana (CDI). Isso requer a vontade dos Estados, ou seja, há a importância das opiniões e ideias dos burocratas da OEA, mas há também a exigibilidade da atitude dos Estados membros. Para Perina (2001), mesmo assim, há uma preocupação dos Estados com o poder da burocracia nas Organizações Internacionais, em especial quanto ao poder do SecretárioGeral, pois:

A eficácia e a eficácia de seu poder dependem da capacidade informal de liderança e formação de consenso de seu Secretário-Geral, uma figura eleito pelos Estados membros a cada cinco anos. Os Estados membros sempre quiseram limitar os poderes da Secretaria Geral e são muito cuidadosos em ceder sua soberania a um poder supranacional. (PERINA, 2001, p. 27 apud FREITAS LACERDA; DE FREITAS, 2018, p. 190).

Sem embargo, existem exemplos de que os relatórios apresentados pelas missões de observação efetivamente contribuem para o aperfeiçoamento dos pleitos, como se extrai do relatório final da missão de observação das Eleições Gerais do Brasil de 2018, no qual foi recomendado o seguinte:

A Missão recomenda o estabelecimento de critérios mais claros para a alocação de recursos públicos dentro dos partidos políticos, que permitam uma 
utilização mais equitativa desses fundos e que promovam o acesso do maior número de mulheres possível aos cargos de escolha popular. Além disso, sugere-se a definição de um regime legal de sanções para aqueles partidos que não cumpram as cotas de gênero, tanto na alocação dos recursos quanto no acesso aos meios de comunicação. É essencial o papel que pode desempenhar o Tribunal Superior Eleitoral na promoção da participação efetiva das mulheres.

A Missão recomenda a criação de uma Unidade de Políticas de Gênero dentro do Tribunal, com os recursos humanos e financeiros suficientes para sustentar a continuidade de ações e programas de longo prazo destinados a aumentar a participação política das mulheres; desenvolver e implementar as funções de monitoramento para observar o cumprimento da aplicação das cotas de gênero e financiamento e promover mensagens e educação cidadã não discriminatória em partidos políticos, meios de comunicação e escolas. (OEA, 2018, p. 22).

Em resposta a tal recomendação, o Tribunal Superior Eleitoral instituiu, através da Portaria $\mathrm{n}^{\mathrm{o}} 791$ de 10 de outubro de 2019, um grupo de trabalho para atuar no planejamento e acompanhamento de medidas que visem diminuir a desigualdade de gênero no Brasil (BRASIL, 2019). ${ }^{11}$

Em alguns outros países, porém, os relatórios de observação parecem ser totalmente desconsiderados, não havendo interesse do Estado-Membro em implementar as sugestões apresentadas. Esse ponto é digno de uma reflexão, posto ser necessário que haja, para o bem do desenvolvimento da democracia, um acompanhamento posterior, com ações efetivas por parte da OEA caso as medidas apresentadas durante a observação não sejam efetivadas.

Por derradeiro, é necessário apontar que a OEA tem apresentado um modelo do que ela entende por democracia, buscando a implantação daquele conceito "universal" para todas as nações. Sabe-se, contudo, que os Estados-Membros da entidade tem origens históricas e etapas de desenvolvimento político distintas, cabendo aqui observar que

Não se discute a necessidade do monitoramento em democracias em que os processos de construção de instituições democráticas por via do sufrágio sejam ainda muito pouco transparentes. O problema parece consistir, porém, em que a prática do monitoramento transforma-se em uma prática de tutela dos processos das chamadas democracias delegativas. As atribuições da Missão Especial, que dá continuidade institucional à MOE-OEA, revela esse fato. Trata-se não de um simples monitoramento, mas de influir na forma e no conteúdo que devem adquirir as instituições estatais. Aqui é relevante voltar a Aron: imiscuir-se nos assuntos internos de um Estado é uma questão de prudência, de oportunidade, e não simplesmente de vontade ou de posicionamento valorativo. Essa não é uma questão irrelevante para os

\footnotetext{
${ }^{11}$ Interessante anotar que, na parte inicial da Portaria, a então Presidente do Tribunal Superior Eleitoral do Brasil fez expressamente constar que o fundamento do ato era "a recomendação da Missão de Observação Eleitoral da Organização dos Estados Americanos MOE/(OEA), ocorrida nas Eleições 2018, de que a Justiça Eleitoral brasileira atue em prol do aumento da efetiva participação das mulheres no cenário político; [...].” (BRASIL, 2019).
} 
estados, porque a saúde das democracias depende muito de que as instituições sejam construídas e reformadas de acordo com a vontade política nacional.

No fundo ainda permanece aquela premissa estadunidense de julgar os processos de modernização política na América Latina à luz de sua própria experiência histórica, o que já tinha sido notado por Samuel Huntington nos anos 1960 no seu quase clássico livro A ordem política em sociedades em mudança: "No confronto com os países em modernização os Estados Unidos levaram a desvantagem de sua história feliz. No seu desenvolvimento os Estados Unidos foram abençoados com abundância econômica, bem-estar social e estabilidade política. Essa agradável conjunção de bençãos levou os americanos a acreditar na unidade do bem, presumindo que todas as coisas boas vão juntas e que a consecução de um objetivo social desejável ajuda a consecução de outros" (HUNTINGTON, 1975, p. 18 apud VILLA, 2003, p. 64).

Parece ser momento para tais questões serem postas na mesa da Assembleia Geral da Organização dos Estados Americanos. As missões poderão ter papel relevante nas próximas décadas, especialmente com o crescimento de movimentos de extrema-direita em países importantes, como o Brasil, o México e a Colômbia.

Vale anotar que acompanhar uma eleição não se resume a apresentar um relatório. É preciso que tenhamos um acompanhamento constante e, caso alguma nação saia da curva prevista pela Carta Democrática Interamericana, a OEA tenha instrumentos para retomar a rota.

Importa anotar que essa rota é igual para todos os países, mas eles têm diferenças e elas precisam ser respeitadas. O caso da Bolívia, nas eleições de 2019 é emblemático. Parece claro que tentou-se fazer o país seguir uma rota que não era a que a população queria. Ela, a população, tem o direito de escolha e o trabalho da OEA é garantir esse direito, não influenciar ou definir qualquer será a escolha.

Ao povo de um país cabe definir seu caminho, contando com as contribuições das organizações internacionais, que devem mostrar às demais nações eventuais desvios de rota. Ela ajuda no caminho, mas não pode definir qual será ele.

\section{Conclusão}

Infelizmente, as nuvens de movimentos antidemocráticos mais uma vez pairam sobre a América Latina, se é que elas deixaram de ser vistas sobre nossas cabeças. Não é preciso ser um sábio para se imaginar que os princípios democráticos defendidos desde a Carta de Organização dos Estados Americanos de 1948 estão sendo questionados (OEA, 2021).

Importante ressaltar que não se pode confundir o direito à democracia com a eleição de um regime, pois 
[...] no contexto da democracia representativa, não há sistema político ou método eleitoral que seja igualmente adequado para todas as nações e seus povos e os esforços da comunidade internacional para reforçar a eficácia do princípio de que a realização de eleições genuínas e episódicas não deva pôr em dúvida o direito soberano de cada Estado de eleger e desenvolver seus sistemas políticos, sociais e culturais livremente, se eles são ou não para a conexão de outros Estados. (COOPER; LEGLER, 2006, p. 29).

Todavia, os questionamentos que têm sido feito por alguns Presidentes, eleitos pelo voto popular, visam minar a própria democracia, e não uma ou outra escolha legislativa realizada.

Nesse contexto, as missões de observação da Organização dos Estados Americanos terá relevante papel, mostrando, através das análises realizadas por seus observadores, com testemunhos e análises, os riscos que a democracia desses países pode estar passando.

A análise externa, porém, precisa ser isenta de preconceitos, realizada por observadores efetivamente livres, sem prévias concepções ou ideologias, evitando questionamentos como o que ocorreu na Bolívia, em 2019, em episódio que abalou a reputação das missões de observação.

É importante também que tais análise mostrem os caminhos, não se limitando apenas a criticar, sem buscar ajudar os Estados-Membros a efetivamente trilhar os anseios insculpidos na Carta Democrática Interamericana. Pela leitura dos relatórios, verificamos que efetivamente tem havido uma melhora nesse sentido, mas a atuação não pode se encerrar apenas com a entrega do relatório final da missão, cabendo à OEA acompanhar efetivamente o desenvolvimento de tais proposições.

Vale também ressaltar a necessidade de alteração de dois pontos da CDI: (i) a possibilidade de realização de missões mesmo em caso de não convite por parte do EstadoMembro, algo que deve ser questionado; e (ii) a criação de mecanismos que possam obrigar os países a cumprirem as recomendações apresentadas nos relatórios de missão.

Tais desafios são imediatos e não podem esperar. A democracia deve ser defendida por todos. Não podemos voltar no tempo e flertar com regimes autoritários. A América Latina ainda tem veias abertas, numa lembrança da obra de Eduardo Galeano, onde corre o sangue de tantos perseguidos por regimes ditatoriais.

Não é dado, às próximas gerações, o regresso a tais tempos sombrios, cabendo a todos, em especial à Organização dos Estados Americanos, uma vigília permanente contra todos que possam representar tal atraso. 


\section{Referências}

BRASIL. Tribunal Superior Eleitoral. Portaria no 791, de 10 de outubro de 2019. Brasília: Tribunal Superior Eleitoral, 2019. Disponível em: https://www.tse.jus.br/legislacao/compilada/prt/2019/portaria-no-791-de-10-de-outubro-de2019. Acesso em: 21 maio 2021.

COOPER, Andrew Fenton; LEGLER, Thomas. Intervention without intervening? The OAS defense and promotion of democracy in the Americas. 1. ed. New York, NY: Palgrave Macmillan, 2006.

DREZZA, Débora Roma. O controle das instituições democráticas por organizações internacionais: análise das aplicações da Carta Democrática Interamericana pela OEA durante o período de 2001 a 2012. 2017. 83 f. Monografia (Trabalho de Conclusão de Curso) - Universidade Presbiteriana Mackenzie, São Paulo, 2017. Disponível em: http://dspace.mackenzie.br/bitstream/handle/10899/18783/D\%C3\%89BORA\%20ROMA\%20 DREZZA..pdf?sequence=1\&isAllowed=y. Acesso em: 21 maio 2021 .

FREITAS LACERDA, Jan Marcel de Almeida; DE FREITAS, Jeane Silva. A atuação da Organização dos Estados Americanos (OEA) e de sua burocracia internacional na defesa da democracia no continente americano. Sociedade e Cultura - Revista de Ciências Sociais, v. 21, n. 2, p. 176-194, ago. 2018. Disponível em:

https://www.redalyc.org/jatsRepo/703/70358824035/70358824035.pdf. Acesso em: 21 maio 2021.

LE DIRECTEUR GÉNÉRAL DES ÉLECTIONS DU QUÉBEC. A observação eleitoral: guia prático para os membros de missões de observação eleitoral no estrangeiro. 2. ed. rev. e aumentada por Madeleine Albert. Québec: DG, [2021]. Disponível em: https://www.electionsquebec.qc.ca/documents/pdf/guide-pour-missions-observationelectorale-portugaise.pdf. Acesso em: 21 maio 2021.

MARQUES, Verônica Teixeira; GALVÃO, Vivianny. O Marco da Carta Democrática Interamericana e sua Interpretação no Processo de Impeachment da Presidente Dilma Rousseff: repensando a Democracia. Revista Direitos Humanos e Democracia, v. 8, n. 15, p. 191-203, jan./jun. 2020. Disponível em:

https://www.revistas.unijui.edu.br/index.php/direitoshumanosedemocracia/article/view/7250/ 6413. Acesso em: 21 maio 2021.

NACIONES UNIDAS. Declaración de principios para la observación internacional de elecciones y Código de conducta para observadores internacionales de elecciones. Nueva York: Naciones Unidas, 27 de octubre de 2005. Disponível em: http://www.eods.eu/library/DoP-SPA.pdf. Acceso en: 21 maio 2021.

OEA - Organização dos Estados Americanos. 50 años observando elecciones en las Américas. [S.1.]: OEA, 2012. Disponível em: http://www.oas.org/es/sap/deco/docs/MOE50y_s.pdf. Acesso em: 21 maio 2021.

OEA - Organização dos Estados Americanos. Análisis de Integridad Electoral - Elecciones generales en el Estado Plurianual de Bolivia - 20 de octubre de 2019. Informe Final. [S.1.]: OEA, 2019b. Disponível em: http://www.oas.org/es/sap/deco/Informe-Bolivia2019/0.1\%20Informe\%20Final\%20-

$\% 20$ Analisis\%20de\%20Integridad\%20Electoral\%20Bolivia\%202019\%20(OSG).pdf. Acesso em: 21 maio 2021. 
OEA - Organização dos Estados Americanos. Anexo 1: acuerdos relativos al análisis de integridad electoral de las elecciones y de privilegios e inmunidades de los expertos -

Invitación del estado plurianual de Bolivia - Respuesta del secretario general de la OEA. [S.1.: s.n.], 2019a. Disponível em: http://www.oas.org/es/sap/deco/Informe-Bolivia-2019/1\%20\%20Acuerdos.pdf. Acesso em: 21 maio 2021.

OEA - Organização dos Estados Americanos. Carta Democrática Interamericana (Aprovada na primeira sessão plenária, realizada em 11 de setembro de 2001). Disponível em: http://www.oas.org/OASpage/port/Documents/Democractic_Charter.htm. Acesso em: 21 maio 2021.

OEA - Organização dos Estados Americanos. Missão de Observação Eleitoral - Eleições Gerais - Brasil. 7 de outubro de 2018 (Eleições Gerais); 28 de outubro de 2018 (Segundo Turno). [S.1: s.n.], 2018. Disponível em: http://scm.oas.org/pdfs/2019/CP40397PRELATORIOFINALMOEBRASIL2018.pdf. Acesso em: 21 maio 2021.

OEA - Organização dos Estados Americanos. Observando los Sistemas de Financiamiento Político-Electoral: Un Manual para las Misiones de Observación Electoral de la Organización de los Estados Americanos. Washington: OEA, 2006. Disponível em: https://www.oas.org/es/sap/deco/pubs/manuales/MOE_Manual_s.PDF. Acesso em: 21 maio 2021.

OEA - Organização dos Estados Americanos. Quem somos. Disponível em: http://www.oas.org/pt/sobre/quem_somos.asp. Acesso em: 21 maio 2021.

OEA - Organização dos Estados Americanos. Departamento de Direito Internacional. Carta da Organização dos Estados Americanos (A-41). Disponível em:

http://www.oas.org/dil/port/tratados_A-

41_Carta_da_Organiza\%C3\%A7\%C3\%A3o_dos_Estados_Americanos.htm. Acesso em: 21 maio 2021 .

SHELTON, D. International Law and Relative Normativity. In: EVANS, M. International Law. Oxford: Oxford University Press, 2010.

THE INTERCEPT BRASIL - Glenn Greenwald. Mídia americana finalmente admite que era falho o relatório da OEA que ajudou a espalhar e levou a golpe na Bolívia. The Intercept Brasil, 9 de junho de 2020. Disponível em: https://theintercept.com/2020/06/09/midiaamericana-oea-eleicao-bolivia/. Acesso em: 21 maio 2021.

VILLA, Rafael A. D. A questão democrática na agenda da OEA no pós-Guerra Fria. Revista de Sociologia Política, [s.1.], n. 20, p. 55-68, 2003. Disponível em:

https://doi.org/10.1590/S0104-44782003000100006. Acesso em: 21 maio 2021. 